\title{
Sport tourist motives: Implications for market segmentation and tourist destination selection
}

\begin{abstract}
The purpose of this research was to identify the motives of sport tourists. The second was to determine if destination attributes could be associated with the aforementioned motives. This study examined the motives of sport tourists in terms of the following dimensions : intellectual (the extent to which an individual is motivated to travel to be involved in activities such as exploring, discovering or creating), social ( the extent to which an individual travels because of the need for friendship and interpersonal relationships), competence-mastery ( the extent to which an individual engages in tourism activities that is challenging, achievement-oriented or competitive in nature), and stimulus-avoidance (the extent to which an individual needs to escape and get away form over-stimulating situations). Data for this study were collected quantitatively from 400 subjects using the Leisure Motivation Scale developed by Ragheb and Beard (1983), designed to measure the psychographic dimensions of sport tourists. The second part of the instrument measures preferred destination attributes. It consists of a 23 pair semantic differential scale which measures various tourist destination attributes developed by Attle \& Yiannakis (1995). Data were analyzed using descriptive statistics and logistic regression. The results were discussed in light of earlier findings concerning sport tourist motivations and preferred destination attributes. Practical implications to tourism marketers were also discussed
\end{abstract}

Keyword: Sport Tourism, Market Segmentation, Tourist Motives, Marketing 